\title{
Measuring intimate partner violence risk: A national survey of Canadian police officers
}

\author{
Michael D. Saxton, ${ }^{*} \dagger$ Peter G. Jaffe, ${ }^{* \dagger}$ Anna-Lee Straatman, ${ }_{, \dagger}^{\dagger}$ Laura Olszowy, ${ }^{* \dagger}$ and Myrna Dawson ${ }^{\ddagger}, \S$
}

\begin{abstract}
This study examined the role of police in addressing intimate partner violence (IPV) and the type of strategies they apply across Canada based on a national survey of officers. The focus was on an examination of the types of structured tools Canadian police officers report using in their risk assessment strategies. The results suggest that Canadian police officers are reporting frequent engagement in risk assessments across jurisdictions. The survey findings indicate variability across provinces in the types of risk assessment tools police officers are using. Implications for future research include exploring specific provincial and territorial police risk assessment processes and the challenges in engaging in risk assessments.
\end{abstract}

Key Words Risk assessment; risk appraisal tools; community policing.

\section{INTRODUCTION}

Police services play an important role in the response to intimate partner violence (IPV). Police officers are often the first responders when there is a domestic dispute and may be the first professional who has contact with the family. Police, therefore, are in a critical position to help survivors immediately, but also over time, as they may be the starting point in referring survivors, perpetrators and children to support and treatment services (Trujillo \& Ross, 2008). There is also a recognition that police officers are the gatekeepers of the criminal justice system (Hamby et al., 2016; Tasca et al., 2013; Saxton et al., 2018). Some even acknowledge police officers' ability to intervene, arrest, and engage in best practices during IPV incidents as providing the groundwork for holding perpetrators accountable for their actions (Hamby et al., 2016). Police officers' obligation to respond to families anywhere, and at any time, places them in a unique position to come into contact with families in situations where other service providers may not have access (Berkman \& Esserman, 2004). Police are in a central position to assess the risk of violence for families and, thereby, be a critical guide to appropriate services and resources for those in need; this includes the ability to intervene on behalf of children present at the scene (Richardson-Foster et al., 2012; Saxton et al., 2020).

\section{Factors Influencing the Police Response}

Many factors influence a police officer's response to IPV. Research into police decision-making has found that both survivor- and offender-specific variables, such as age, socioeconomic status, sex, and ethnicity, can potentially influence police responses to IPV (Avakame \& Fyfe, 2001; Bachman \& Coker, 1995; Ferraro, 1989; Hamilton \& Worthen, 2011; Lee et al., 2013; Saxton et al., 2018; Robinson \& Chandek, 2000; Trujillo \& Ross, 2008). Research also points to situational factors that shape police decision-making processes. Here, factors related to evidence, such as the type and severity of violence, as well as situational characteristics, including the presence of children, a weapon, or drugs and alcohol, can all impact police decision-making (Bachman \& Coker, 1995; Buzawa \& Austin, 1993; Dawson \& Hotton, 2014; Mignon \& Holmes, 1995; Robinson \& Chandek, 2000; Saxton et al., 2018; Saxton et al., 2020; Trujillo \& Ross, 2008). Police decisions are also directly influenced by the policies and practices established within a police service as well as by local or federal authorities (Eitle, 2005).

\section{Policing Intimate Partner Violence in Canada}

In Canada, police policy towards IPV has evolved over the last three decades. In 1986, the Attorneys General and Solicitors General across all jurisdictions issued directives to police services to ensure that IPV cases were treated as

\footnotetext{
Correspondence to: Michael Saxton, Centre for Research \& Education on Violence Against Women \& Children, Western University, 1137 Western Road, Room 1158 Faculty of Education Building, London, ON N6G 1G7. E-mail: msaxton@uwo.ca

To cite:Saxton, M. D., Jaffe, P. G., Straatman, A.-L., Olszowy, L., \& Dawson M. (2020). Measuring intimate partner violence risk: A national survey of Canadian police officers. Journal of Community Safety and Well-Being, 5(3), 103-109. https://doi.org/10.35502/jcswb.144

@ Author(s) 2020. Open Access. This work is distributed under the Creative Commons BY-NC-ND license. For commercial re-use, please contact sales@sgpublishing.ca.
}

Sg PUBLISHING Published by SG Publishing Inc. CSKA Official publication of the Community Safety Knowledge Alliance. 
criminal matters (Department of Justice, 2003). Although this directive was implemented with some variability across police services, police force policies were generally put into place requiring officers to lay charges where reasonable and probable grounds of an assault had taken place (Department of Justice, 2003).

Today, charging and prosecution policies on IPV remain in effect in all provinces and territories in Canada. While there is no national charging or prosecutorial policy on IPV, all jurisdictions continue to support a similar police and justice system response (Department of Justice, 2003); that is, the primary objective is to criminalize IPV (Department of Justice, 2003). In this way, police policies towards IPV in Canada are directed at both general and specific deterrence; the general deterrence is through the strong and clear message to society that IPV is wrong; and the specific deterrence is through the pursuit to prevent perpetrators from committing further acts of violence (Department of Justice, 2003). In the majority of Canadian provinces and territories, police standards have been developed to ensure a minimum standard of practice across services. While there is some variability across provincial mandates, these standards provide directives regarding the response to IPV (i.e., risk assessment, training, and coordination).

\section{Police and Risk Assessment}

Police action and officers' decision-making processes in IPV interventions have been a central focus in the literature, with researchers highlighting the impact of police judgments on future violence, specifically on reducing its likelihood (Buzawa \& Buzawa, 2003; Felson et al., 2005; Hovell et al., 2006; Maxwell et al., 2001; 2002; Schmidt \& Sherman, 1996; Trujillo \& Ross, 2008). Researchers have demonstrated that police officers' perceptions of the risk of future violence and the imminence of that violence are highly influential factors impacting decisions in IPV situations (Campbell et al., 2018; Storey et al., 2014; Trujillo \& Ross, 2008). Research has also shown that when no structured assessment (i.e., validated risk assessment tool) is used in assessing the risk of violence, the resulting judgments are often inaccurate (Campbell et al., 2018). Likewise, a lack of assessment can directly lead to reduced risk management and intervention planning (Bonta \& Andrews, 2010; Hanson, 2009). A validated risk assessment tool provides police officers with another tool that aids not only in recognizing risks posed to a family but also in identifying the appropriate level of response, both of which are crucial aspects of keeping families safe.

Research evaluating the validity of various IPV risk assessment tools is still growing. The literature has found modest predictive validity among the various tools (for reviews see Messing \& Thaller, 2013; Nicholls et al., 2013; Helmus \& Bourgon, 2011). Though predictive validity is an important test of efficacy as it measures a tool's accuracy in predicting the likelihood of future violence, other factors should be considered when choosing a risk assessment instrument. For instance, factors like the professional context, access to information, and cultural appropriateness should all be considered (Kropp \& Hart, 2015; Messing \& Thaller, 2013). Accordingly, further research is needed in evaluating risk assessment tools, particularly in a policing context.

\section{Police, Risk Management, and Safety Planning}

Researchers and practitioners acknowledge that risk assessments are not an end in themselves but an ongoing process to inform appropriate risk management strategies (Campbell et al., 2016). Risk assessments are viewed as being the crucial initial step in the process of helping to identify appropriate supervision strategies, develop more effective safety plans for survivors, and guide risk management and rehabilitative options for perpetrators (Messing, 2019; Humphreys et al., 2005; Hoyle, 2008).

Overall, the increased use of risk assessment is viewed positively by police services, as it can provide a basis for more targeted and efficient responses to IPV (Radford \& Gill, 2006; Hoyle, 2008; Grant \& Rowe, 2011). An effective response to IPV involves a combination of risk assessment, risk management, and safety planning. By engaging in these processes, one is in a better position to ensure the safety of survivors and children, as well as address the perpetrators' behaviours and needs (Campbell et al., 2016).

\section{Current Study}

Due to their unique role in the system, it is critical that police officers recognize the risk posed to survivors and their children to better ensure their safety. Part of this recognition comes through police officers' use of risk assessment instruments. While interest in risk assessment tools continues to grow around the world, including in Canada, there remains little research on how police officers are implementing these tools (Kropp, 2004; Humphreys et al., 2005; Hoyle, 2008; Trujillo, \& Ross, 2008). Likewise, little is known about how police officers assess risk in family violence situations and how situational factors contribute to these assessments of risk (Trujillo \& Ross, 2008). Much of the research has focused on the predictive accuracy of risk assessment tools, and there is a scarcity of research examining whether police are engaging in risk assessment, the type of tools they use, and the impacts of risk assessment on risk management and safety planning with diverse families.

To help fill this research gap, the current study explored the following: 1) the frequency with which Canadian police officers are engaging in risk assessment in the context of IPV; 2) the type of instruments police officers are using to assess risk in Canada; 3) the frequency with which Canadian police officers are engaging in risk management and safety planning practices in their role; and 4) the relationship between the use of structured tools, the province in which police worked, and the type of community served (i.e., urban versus rural).

\section{METHOD}

\section{Overview}

The survey used for this study was part of an ongoing research initiative: the Canadian Domestic Homicide Prevention Initiative with Vulnerable Populations (CDHPIVP; for more information see www.cdhpi.ca). The overall purpose of this initiative was to identify protocols and strategies that will reduce the risk of lethal IPV and share this knowledge with the broader community. The project also focused on four identified vulnerable populations: Indigenous populations, children exposed to IPV, immigrants and refugees, and rural, remote, and northern populations. The CDHPIVP 
endeavoured to gain a deeper understanding of potentially unique risk factors, barriers to effective risk assessment, risk management, and safety planning, as well as strategies currently being used by a cross-section of professionals.

\section{Participants}

In total, 1,445 participants completed the survey, most in English ( $n=1,395,96.5 \%)$. Of these participants, $77(5.3 \%)$ indicated that they worked in the "police" sector; this subsample of respondents was used for the current study. Of the police sample, half were from Ontario and identified working within an urban setting only (Table I).

\section{Measures}

Questions on the survey aimed to explore broadly the type of practices participants engage in regarding risk assessment, risk management and safety planning within different sectors across Canada. These questions were created and reviewed by experts in the justice sector, in the violence against women sector, in psychology, and in social work and were exploratory in nature. Additionally, definitions were created and provided on the survey for each corresponding question (Table II). The survey was distributed and promoted through CDHPIVP's partners and collaborators, who represent a wide range of partners from academia, frontline professionals, the justice sector, the violence against women sector, cultural groups, Indigenous sectors, and settings from across Canada. The survey was available in both official languages of Canada (i.e., English and French) and prepared for completion on the Qualtrics survey platform (qualtrics.com). The survey

TABLE I Sample characteristics for police respondents

\begin{tabular}{lr}
\hline Province groups & \\
Ontario & 50.6 (39) \\
Western (Manitoba to British Columbia) & 35.1 (27) \\
Maritimes & 9.1 (7) \\
Quebec & $2.6(2)$ \\
Territories & $2.6(2)$ \\
Type of community served & \\
\hline
\end{tabular}

Urban only

Rural, remote, or northern $45.5(35)$ consisted of 10 multiple-choice questions focused on frontline professionals' experiences with responding to IPV as well as the types of vulnerable populations with which they work. Participants were asked how often they engage in risk assessment, risk management, and safety planning in the context of IPV. Participants were asked about their use of structured tools (yes or no response) and were provided space for an open-ended response to identify the types of tools they use. Additional space was offered to participants to provide further comments about their experiences.

The survey was also designed to be used as part of a recruitment process to access key informants for further, more detailed interviews (see Saxton et al., 2020). At the end of the survey, participants could provide their contact information to be included in the second phase of this project. Given the exploratory nature of this research study, the survey was developed to obtain a snapshot of frontline professionals' risk assessment, risk management, and safety planning strategies in addressing IPV. As such, there is currently no reliability or validity data on the survey employed. Before the launch, the survey was given to numerous IPV experts as well as professionals working across sectors to test for clarity.

\section{Data Analysis}

Three graduate research assistants analysed open-ended responses to group the types of structured tools. Discrepancies were discussed until consensus was reached, though most were clearly labelled and easily classified. Descriptive statistics were completed on the frequencies of the strategies used by police in their response to IPV, the type of vulnerable populations they work with, and the use of structured risk assessment tools. An ordinal regression analysis was completed to determine whether using a structured risk assessment tool increased the frequency of risk assessment engagement. Chi-square tests of independence were used to compare province and community served (i.e., rural or urban) and the use of a structured risk assessment tool. Bonferroni adjustments were used across all comparisons due to small sample sizes. All data were analyzed using SPSS 24.

\section{RESULTS}

Overall, police officers in this sample were found to work frequently with different populations. For instance, $44 \%$ of participants indicated that they regularly work with children in their role as a police officer (Figure 1). While there were

TABLE II Project definitions for risk assessment, risk management, and safety planning

$\begin{array}{ll}\text { Risk assessment } & \begin{array}{l}\text { Evaluating the level of risk of harm a survivor may be facing including the likelihood of repeated violence or lethal } \\ \text { (dangerous) violence, based on a professional's judgment and/or a structured interview and/or a tool (instrument) } \\ \text { that may include a checklist of risk factors. }\end{array} \\ \text { Risk management } & \begin{array}{l}\text { Strategies to reduce the risk presented by a perpetrator of domestic violence such as close monitoring or supervision, } \\ \text { counselling to address the violence and/or related issues, such as mental health and addictions. }\end{array} \\ \text { Safety planning } & \begin{array}{l}\text { Finding strategies to protect the survivor by actions such as a change in residence, an alarm for a higher priority po- } \\ \text { lice response, a different work arrangement and/or readily accessible items needed to leave home in an emergency } \\ \text { including contact information about local domestic violence resources }\end{array}\end{array}$

For more details on definitions see Campbell et al., 2016. The term domestic violence was used within this study. 




FIGURE 1 Frequency with which participants work with different vulnerable populations

some slight differences observed, most participants in this sample were found to work at similar rates with Indigenous people, immigrants, refugees, and newcomers to Canada (Figure 2). Approximately $45 \%$ of the sample indicated that they served rural, remote, or northern communities. There were no significant differences in terms of frequencies of populations police work with, the province where they are located, or the community they serve (i.e., urban or rural).

Risk Assessment, Risk Management, and Safety Planning Police officers were asked about the type of strategies they engage in when responding to IPV occurrences. Overall, the majority of police officers indicated that they frequently engage in risk assessment and management-related strategies for IPV. While fewer police officers indicated using safety planning in their role, a sizable number indicated they frequently $(42.5 \%)$ engaged in safety planning during IPV occurrences, as defined by this project.

\section{Structured Tools}

The majority $(72.7 \%, n=56)$ of this sample indicated that they used a structured risk assessment tool in their roles as police officers. Overall, a large variety of tools were identified as being used by police from across Canada (Figure 3). The most frequently identified instrument was the Ontario Domestic Assault Risk Assessment. This may be due to the larger response rate by police officers working in Ontario. Several participants also indicated using multiple instruments in their risk assessment approaches to IPV calls for service. Subsequent analysis was undertaken to examine whether the use of a structured tool was associated with increased frequency in risk assessment engagement. An ordinal regression examining the relationship between using a structured tool and the frequency of engaging in risk assessment was approaching significant $(p=.07)$. Those indicating the use of a structured tool were more frequently completing risk assessments, though caution is warranted in drawing conclusions. No differences were observed between provinces or communities served and the use of a structured tool.

\section{DISCUSSION}

The current study was part of a large-scale study examining frontline professionals' use of risk assessment, risk management, and safety planning strategies to aid in the prevention of intimate partner violence/homicides. Using a sample of

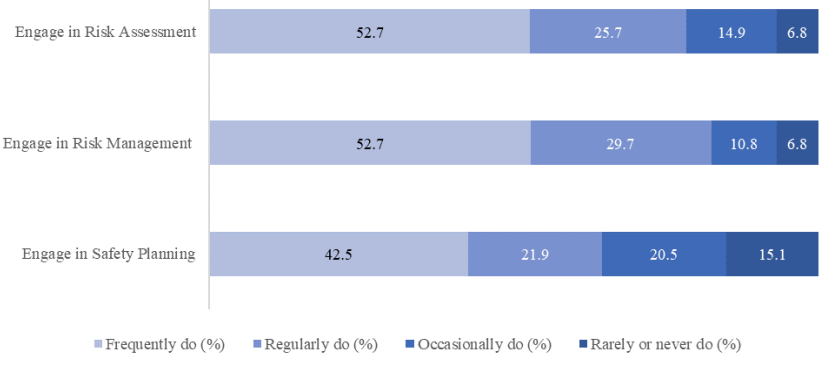

FIGURE 2 Frequency of use of risk assessment, risk management, and safety planning strategies

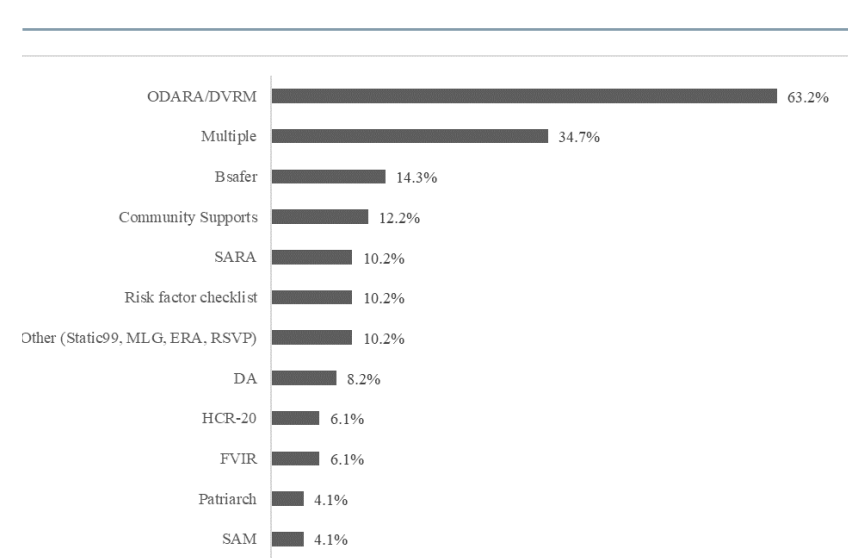

FIGURE 3 Types of risk assessment tools used identified by police officers. ODARA: Ontario Domestic Assault Risk Assessment; DRVM: Domestic Violence Risk Management, which contains the ODARA; B-SAFER: Brief Spousal Assault Form for the Evaluation of Risk; SARA: Spousal Assault Risk Assessment Guide; DA: Danger Assessment; HCR-20: The Historical Clinical Risk Management; FVIR: Family Violence Investigation Report; Patriarch: Risk for Honour-Based Violence; SAM: Stalking Assessment and Management; MLG: Multi-Level Guidelines; ERA: Environmental risk assessment; RSVP: Risk for Sexual Violence Protocol

police officers from Canada, this exploratory study focused on the police response to IPV, the strategies Canadian police officers adopted in the prevention of violence, and how community factors impact these strategies. Broadly, results indicated that police self-report that they are often engaging in risk assessment and risk management in their response to IPV. Officers in this sample reported engaging in safety planning strategies at a lesser frequency than they did risk assessment and management. The majority of police officers indicated that they used a structured assessment tool to assess risk in IPV occurrences. The use of a structured tool may increase engagement in risk assessment strategies for police. The most common tool identified was the Ontario Domestic Assault Risk Assessment (ODARA; Hilton et al., 2010).

Findings from this study revealed substantial variability in the types of structured tools being used across provinces. Several respondents identified structured tools that were outside the generally accepted definition (i.e., community supports, risk factor checklist). This speaks to potential confusion regarding not only the type of risk appraisal processes police are engaging in, but also how frontline professionals come to define their response to IPV. However, the current study was 
unable to examine officer knowledge about IPV and IPV risk assessment due to the limitations of its design. Nevertheless, it is essential to understand police officers' perceptions of risk assessment, given that previous research has found that their view of risk assessment tools can shape how they deal with IPV cases (Ballucci et al., 2017).

There are some limitations to the current study. First are those pertaining to the sample. While this study was part of a larger research project, the small sample of police officers recruited was heavily based in Ontario. Therefore, the generalizability to the rest of Canada is questionable. The potential impact of volunteer bias based on those who chose to participate is another limitation. Additionally, the specific motivation of the sample of police officers was not captured, nor were their overall background, training, or experience with responding to IPV occurrences. Though exploratory, this study also lacked information about the specific role police officers played in IPV occurrences and the nuanced details related to the assessment and management of risk for families experiencing IPV. Further complicating the matter are differences in specific provincial policies and police standards. Overall, this lack of detail makes it challenging to draw conclusions from the current study's data. It does, however, provide direction for future research.

Despite the current study's limitations, it examines a crucial aspect of the public response to IPV, which is the police response, something that continues to be under-studied. Overall, this study revealed that police officers frequently use structured tools to assess risk in IPV occurrences and that they engage in risk management and safety planning strategies. However, it is not clear what these strategies, processes, and protocols look like for police officers at the ground level. Additionally, despite the definitions provided, it is speculated that there is a vast discrepancy in how police officers qualify their use of risk assessment, risk management, and safety planning strategies. This concern further highlights the need to develop a deeper understanding of both the role of police and their real actions in response to IPV. This study found that police frequently work with diverse populations, highlighting the increasing importance of examining how police are considering the needs of diverse populations, including the risk posed to children (Jaffe et al., 2012).

There is an overall acknowledgement that risk assessment is not an end in itself, but rather an ongoing process that informs appropriate strategies. Risk assessment is viewed as being the crucial initial step in the process of helping to identify appropriate supervision strategies, develop more effective safety plans for survivors, and guide management as well as rehabilitative options for perpetrators. More recently, there has been a movement towards using risk assessment as a critical first step to inform collaboration with other services. A risk-informed collaborative intervention is an essential approach in the prevention of escalating IPV through an increased coordinated systems response (Campbell et al., 2009; Messing \& Campbell, 2016; Messing, 2019; Ward-Lasher et al., 2017).

System collaboration is critical to ensuring information sharing that is comprehensive and communicated to all stakeholders. Researchers have suggested developing a common risk assessment tool to enhance communication of risk across systems (Stanley \& Humphreys, 2014). Others have endorsed the use of high-risk case coordination protocols, whereby justice partners and other key stakeholders meet to discuss families identified as high risk (Department of Justice Canada, 2003). Examples of these teams have emerged around the world, including the Lethality Assessment Program (LAP) in the United States, the multi-agency risk assessment conferences (MARACs) in the United Kingdom, and the Interagency Case Assessment Teams (ICATs) in Canada. These programs show promise as collaborative approaches that more comprehensively address the needs of families experiencing IPV. However, further evaluation is warranted.

Future considerations should include examining the appropriateness of formal risk assessment tools, particularly in the police response to IPV. Indeed, the consistent use of valid risk assessment in policing has several important implications. Perhaps the most significant is that it encourages police to look methodically at cases of IPV to determine the whole picture (Messing, 2019). There is a subsequent need for risk assessments to be completed correctly and consistently to ensure police officers are gaining information that can allow them to make informed decisions about the risk present in IPV incidents and inform prosecutors regarding important decisions about bail and release terms (e.g., no-contact orders; Hoyle, 2008). Furthermore, there is a need to evaluate how differences in police officers specially trained in IPV (i.e., IPV specialists) approach IPV occurrences compared with those who lack specialized training (i.e., generalists). Critical, here, is determining whether a more specialized unit positively impacts the reduction of IPV occurrences as well as the quality of police assessment and intervention (Segrave et al., 2018). Future research should examine the barriers to effective risk assessment in the context of police and IPV in terms of potential issues of training and resources.

\section{CONCLUSION}

Given the evolution in policies and protocols for IPV and police, it is not surprising that there has been an increased use of risk assessment by police officers. What was more surprising was the indication that police officers are also frequently engaging in other risk management and safety planning strategies. This is encouraging given the call for moving beyond focusing on simply administering risk assessments to using the results to improve responses. The results in the current study show promise that risk assessment is not an end in itself for police officers in Canada. However, it is still early to draw conclusions, and a great deal more needs to be done to understand how police conduct risk assessment practices.

\section{ACKNOWLEDGEMENTS}

This research was supported by the Social Sciences and Humanities Research Council of Canada.

\section{CONFLICT OF INTEREST DISCLOSURES}

The authors declare no potential conflicts of interest.

\section{AUTHOR AFFILIATIONS}

*Western University, London, $\mathrm{ON} ;{ }^{\dagger}$ Centre for Research \& Education on Violence Against Women and Children, London, ON; \#University of Guelph, Guelph, ON; §Centre for the Study of Social and Legal Responses to Violence, Guelph, ON. 


\section{REFERENCES}

Avakame, E. F., \& Fyfe, J. J. (2001). Differential police treatment of maleon-female spousal violence: Additional evidence on the leniency thesis. Violence against Women, 7(1), 22-45.

Bachman, R., \& Coker, A. L. (1995). Police involvement in domestic violence: The interactive effects of victim injury, offender's history of violence, and race. Violence and Victims, 10(2), 91-106.

Ballucci, D., Gill, C., \& Campbell, M. A. (2017). The power of attitude: The role of police culture and receptivity of risk assessment tools in IPV calls. Policing: A Journal of Policy and Practice, 11 (3), 242-257.

Berkman, M., \& Esserman, D. (2004). Police in the lives of young children exposed to domestic violence. In S. Schecter (Ed.), Early childhood, domestic violence, and poverty: Helping young children and their families. lowa City: University of lowa.

Bonta, J., \& Andrews, D. A. (2010). Viewing offender assessment and rehabilitation through the lens of the risk-need-responsivity model. In McNeill, F., Raynor, P., Trotter, C. (Eds.), Offender supervision: New directions in theory, research and practice (pp. 19-40). Oxon, UK: Willan.

Buzawa, E. S., \& Austin, T. (1993). Determining police response to domestic violence victims: The role of victim preference. American Behavioral Scientist, 3615), 610-623.

Buzawa, E. S., \& Buzawa, C. G. (2003). Domestic violence: The criminal justice response (3rd edition). Thousand Oaks, CA: Sage.

Campbell, M. A., Gill, C., \& Ballucci, D. (2018). Informing police response to intimate partner violence: Predictors of perceived usefulness of risk assessment screening. Journal of Police and Criminal Psychology, 33(2), 175-187.

Campbell, M., Hilton, N. Z., Kropp, P. R., Dawson, M., \& Jaffe, P. (2016). Domestic violence risk assessment: Informing safety planning \& risk management. Domestic Homicide Brief. Retrieved from: http://cdhpi. $\mathrm{ca} /$ domesticviolence-risk-assessment-informing-safetyplanning-riskmanagement-brief

Campbell, J. C., Webster, D. W., \& Glass, N. (2009). The danger assessment: Validation of a lethality risk assessment instrument for intimate partner femicide. Journal of Interpersonal Violence, 24(4), 653-674.

Dawson, M., \& Hotton, T. (2014). Police charging practices for incidents of intimate partner violence in Canada. Journal of Research in Crime and Delinquency, 51151, 655-683.

Department of Justice Canada. (2003). Final Report of the Ad Hoc Federal-Provincial-Territorial Working Group Reviewing Spousal Abuse Policies and Legislation. Retrieved from: https://justice.gc.ca/ eng/rp-pr/ci-jp/fv-vf/pol/p2.html

Department of Justice Canada. (2013). Making the links in family violence cases: Collaboration among the family, child protection and criminal justice systems. Retrieved from: http://www.justice.gc.ca/eng/rp-pr/ ci-jp/fv-vf/mlfvc-elcvf/vol2/mlfvc2-elcvf2.pdf

Eitle, D. (2005). The influence of mandatory arrest policies, police organizational characteristics, and situational variables on the probability of arrest in domestic violence cases. Crime \& Delinquency, 51(4), 573-597.

Ferraro, K. J. (1989). Policing woman battering. Social Problems, 36(1), $61-74$

Felson, R. B., Ackerman, J. M., \& Gallagher, C. A. (2005). Police intervention and the repeat of domestic assault. Criminology, 43(3), 563-588.

Grant, S., \& Rowe, M. (2011). Running the risk: Police officer discretion and family violence in New Zealand. Policing \& Society, 21 (1), 49-66.

Hamby, S., Weber, M. C., Grych, J., \& Banyard, V. (2016). What difference do bystanders make? The association of bystander involvement with victim outcomes in a community sample. Psychology of Violence, 6(1), 91.
Hamilton, M., \& Worthen, M. G. (2011). Sex disparities in arrest outcomes for domestic violence. Journal of Interpersonal Violence, 26(8), 1559-1578.

Hanson, R. K. (2009). The psychological assessment of risk for crime and violence. Canadian Psychology, 50131, 172.

Helmus, L., \& Bourgon, G. (2011). Taking stock of 15 years of research on the Spousal Assault Risk Assessment Guide (SARA): A critical review. International Journal of Forensic Mental Health, 10(1), $64-75$.

Hilton, N. Z., Harris, G. T., Popham, S., \& Lang, C. (2010). Risk assessment among incarcerated male domestic violence offenders. Criminal Justice and Behavior, 37|8), 815-832.

Hoyle, C. (2008). Will she be safe? A critical analysis of risk assessment in domestic violence cases. Children and Youth Services Review 30(3), 323-337.

Hovell, M. F., Seid, A. G., \& Liles, S. (2006). Evaluation of a police and social services domestic violence program: Empirical evidence needed to inform public health policies. Violence against Women, 12(2), 137-159.

Humphreys, C., Thiara, R. K., Regan, L., Lovett, J., Kennedy, L., \& Gibson, A. (2005). Prevention not prediction: An evaluation of the Metropolitan Police risk assessment model. Retrieved from: https://cwasu. org/wp-content/uploads/2016/07/ACPO_PreventionnotPrediction 2005.pdt

Jaffe, P. G., Campbell, M., Hamilton, L. H., \& Juodis, M. (2012). Children in danger of domestic homicide. Child Abuse \& Neglect, 36(1), 71-74.

Kropp, P. R. (2004). Some questions about spousal violence risk assessment. Violence Against Women, 10, 696-697.

Kropp, P. R., \& Hart, S. D. (2015). User manual for version 3 of the Spousal Assault Risk Assessment Guide (SARA-V3). Vancouver, BC: Protect International, Inc.

Lee, J., Zhang, Y., \& Hoover, L. T. (2013). Police response to domestic violence: Multilevel factors of arrest decision. Policing: An International Journal of Police Strategies \& Management, 36(1), 157-174.

Maxwell, C., Garner, J., \& Fagan, J. (2001). The effects of arrest on intimate partner violence: New evidence from the spouse assault replication program. Washington, DC: National Institute of Justice.

Maxwell, C. D., Garner, J. H., \& Fagan, J. A. (2002). The preventive effects of arrest on intimate partner violence: Research, policy and theory. Criminology \& Public Policy, 2(1), 51-80.

Messing, J. T. (2019). Risk-informed intervention: Using intimate partner violence risk assessment within an evidence-based practice framework. Social Work, 64(2), 103-112.

Messing, J. T., \& Campbell, J. (2016). Informing collaborative interventions: Intimate partner violence risk assessment for front line police officers. Policing: A Journal of Policy and Practice, 10(4), 328-340.

Messing, J. T., \& Thaller, J. (2013). The average predictive validity of intimate partner violence risk assessment instruments. Journal of Interpersonal Violence, 28(7), 1537-1558.

Mignon, S. I., \& Holmes, W. M. (1995). Police response to mandatory arrest laws. Crime \& Delinquency, 41(4), 430-442.

Nicholls, T. L., Pritchard, M. M., Reeves, K. A., \& Hilterman, E. (2013). Risk assessment in intimate partner violence: A systematic review of contemporary approaches. Partner Abuse, 4(1), 76-168

Radford, L., \& Gill, A. (2006). Losing the plot? Researching community safety partnership work against domestic violence. The Howard Journal of Criminal Justice, 45(4), 369-387.

Richardson-Foster, H., Stanley, N., Miller, P., \& Thomson, G. (2012). Police intervention in domestic violence incidents where children are present: Police and children's perspectives. Policing and Society, 22(2), 220-234. 
Robinson, A. L., \& Chandek, M. S. (2000). The domestic violence arrest decision: Examining demographic, attitudinal, and situational variables. Crime \& Delinquency, 46(1), 18-37.

Saxton, M. D., Jaffe, P. G., Dawson, M., Olszowy, L., \& Straatman, A. L. (2020). Barriers to police addressing risk to children exposed to domestic violence. Child Abuse \& Neglect, 106, 104554

Saxton, M. D., Jaffe, P. G., Dawson, M., Straatman, A. L., \& Olszowy, L. (2020). Complexities of the police response to intimate partner violence: Police officers' perspectives on the challenges of keeping families safe. Journal of Interpersonal Violence, 0886260520934428

Saxton, M. D., Olszowy, L., MacGregor, J. C., MacQuarrie, B. J., \& Wathen, C. N. (2018). Experiences of intimate partner violence victims with police and the justice system in Canada. Journal of Interpersonal Violence, 0886260518758330.

Segrave, M., Wilson, D., \& Fitz-Gibbon, K. (2018). Policing intimate partner violence in Victoria (Australia): Examining police attitudes and the potential of specialisation. Australian \& New Zealand Journal of Criminology, 51(1), 99-116.
Schmidt, J. D., \& Sherman, L. W. (1996). Does arrest deter domestic violence? In E. Buzawa \& C. G. Buzawa (Eds.), Do arrests and restraining orders work?, pp. 43-53. Thousand Oaks, CA: Sage Publications.

Stanley, N., \& Humphreys, C. (2014). Multi-agency risk assessment and management for children and families experiencing domestic violence. Children and Youth Services Review, 47, 78-85.

Storey, J. E., Kropp, P. R., Hart, S. D., Belfrage, H., \& Strand, S. (2014). Assessment and management of risk for intimate partner violence by police officers using the brief spousal assault form for the evaluation of risk. Criminal Justice and Behavior, 41(2), 256-271.

Tasca, M., Rodriguez, N., Spohn, C., \& Koss, M. P. (2013). Police decision making in sexual assault cases: Predictors of suspect identification and arrest. Journal of Interpersonal Violence, 28(6), 1157-1177.

Trujillo, M., \& Ross, S. (2008). Police response to domestic violence: Making decisions about risk and risk management. Journal of Interpersonal Violence, 23(4), 454-473.

Ward-Lasher, A., Messing, J. T., \& Hart, B. (2017). Policing intimate partner violence: Attitudes toward risk assessment and collaboration with social workers. Social work, 62(3), 211-218. 